\title{
HICSS-54 Minitrack Introduction Digital Transformation and Government: Barriers to and Enablers of Change
}

\author{
Margit Scholl \\ Technische Hochschule Wildau, \\ Germany \\ mscholl@th-wildau.de
}

\author{
Jerald Hughes \\ University of Texas Rio Grande, \\ Valley, USA \\ j.hughes@utrgv.edu
}

\author{
Suha AlAwadhi \\ Kuwait University, \\ Kuwait \\ s.alawadhi@ku.edu.kw
}

\begin{abstract}
This minitrack focuses on how digital transformation happens in government, fundamentally changing how government information and services operate and deliver value to citizens and organizations. It sets out to explore the complexities of effectively governing, organizing, and managing the transformational potential of digital and smart government. Increasingly, this process involves interorganizational collaboration and the co-creation of value, multi-sectoral and crossjurisdictional networks, and the management of a large variety of sometimes conflicting relationships with internal and external stakeholders. To define future research directions and practice and identify the implications for governments, communities, and society at large, it is important to develop an improved understanding of the barriers to and enablers of digital transformation and innovation.
\end{abstract}

\section{Introduction}

All our minitracks focus on an eminently practical question while keeping in mind the scientific theoreticcal basis: given the enormous potential that digital technologies evidently have to transform government services, how can the goals of digital transformation projects and the changes in the processes actually be achieved? Our submitting authors responded with a variety of approaches, addressing different technologies in different contexts and involving multiple stakeholders in complex relationships.

This year the minitrack had nineteen submissions. One paper has been withdrawn, four papers were given to other minitracks because they were a better fit for them, and two papers had to be desk-rejected. From the remaining twelve papers, we were looking for highquality conference papers that demonstrate the wide range of approaches to content and case studies as a means to advance this research area with its focus on digital transformation. Based on the standard parameters of rigor and quality, seven papers were accepted for the HICSS-54 in 2021.

These papers include studies on the problems faced by emerging democracies, digital information for local municipalities, creative problem solving in the public sector, evidence-based environmental policy making through data analytics, value co-creation with citizens, improvement of public procurement processes, and cognitive computing systems in the public sector. There are six case studies and one analytical paper, studying digital transformation in the Western Balkan region, Germany, the United States, Norway, and Ghana.

\section{Accepted papers}

"Best Practice of Digital Government in Emerging Democracies: Illustrations, Challenges, and Reflections of State-Building Processes" is authored by Elin Wihlborg, Carl-Johan Sommar, Aneta Kulanovic, Ahmed Kaharevic, and Helena Iacobaeus. This paper employed a collaborative educational methodology to investigate eGovernment maturity within recently founded democracies. This not only showed promising advances but also exposed the problems that have prevented the full promise of the digital turn from manifesting. The authors make it clear that while some best practices may look advanced and integrative, an in-depth examination of them reveals that they do not fully meet the expectations placed on them. As followup research, the authors also recommend studying how welfare schemes impact eGovernment maturity.

"Challenges, Barriers, and Approaches for Providing Digital Citizen Information: A Case-Study in North Rhine-Westphalia, Germany" is authored by Fabian Birghan, Robert Hettenhausen, and Christine Meschede. Their case study, based on a participant questionnaire, looked at systems for providing digital information to citizen. The authors identify six key 
approaches to overcoming barriers at this level. Their evaluation revealed the challenges that exist even in business sectors, whereby the options that are currently available do not seem to meet citizen expectations. The authors summarize the situation, highlighting that a lack of resources in public administrations makes it difficult for them to push ahead and offer a broader range of citizen-oriented services, and recommend a stronger focus on collaboration between municipalities.

"Cultivating Creativity: Insights from German Local Governments about the Drivers and Barriers of Change” is authored by Hans Christian Klein, Frederike Marie Oschinsky, and Sarah Rubens. This paper uses focus group data to identify four main themes that determine the drivers and barriers associated with cultivating creativity in the public sector. The authors present best practices in German local government in order to better understand creative work and its drivers and barriers in public organizations. One aspect of their summary is that public sector workers need to be made aware that creative skills can be learned.

"Towards Data-Driven Decision-Making in Government: Identifying Opportunities and Challenges for Data Use and Analytics” is authored by Yongjin Choi, J. Gil-Garcia, G. Brian Burke, Jim Costello, Derek Werthmuller, and Oguz Aranay. This study of data-driven environmental policy looks at data, technology, organization, and institutions and identifies nine factors that determine outcomes in the application of data analytics in the public sector. The authors delineate the opportunities and challenges involved by focusing on a state agency. The nine determinants that they identified reveal practical issues that public organizations can face when attempting to adopt or implement data-driven decision making. The authors believe that a better understanding of the determinants can help government agencies get off to a running start. Moreover, their findings point to two additional theoretical aspects.

"Using Digital Platforms to Promote a ServiceOriented Logic in Public Sector Organizations: A Case Study" is authored by Kathrine Vestues, Marius Mikalsen, and Eric Monteiro. This paper conducts a longitudinal case study of the IT department at the Norwegian Labor and Welfare Administration (NAV) in an attempt to address the research question "How do digital platforms promote process-oriented, emergent value co-creation in public sector organizations?” The authors' motivation is that the extant literature pays limited attention to the emergent and process-oriented nature of value co-creation. By contrast, their paper explores value co-creation as a process of continuous improvement and looks at the importance of digital platforms in increasing the efficiency of co-creation.
"Digital Transformation Initiative in a Public Sector Organization: Stakeholder Viewpoints and Responses in Ghana” is authored by Michael Agbeko, John Effah, and Richard Boateng. This paper uses stakeholder theory to examine how a public sector transformation initiative in public procurement is shaped by various stakeholder viewpoints and responses. Several outcomes of the paper may influence research and practice and have implications for policy in the future, so the study enriches the literature in the context of the digital transformation of the public sector. One conclusion the authors arrive at is that it is extremely important that government institutions take the reservations of stakeholders seriously when implementing digital government initiatives. The authors emphasize that this gives politicians useful feedback, helping them develop strategies to increase the effective handling of initiatives for digital transformation.

"Maturity Model for Cognitive Computing Systems in the Public Sector” is authored by Kevin C. Desouza, Franziska Götz, and Gregory S. Dawson. This paper uses an approach from design science to develop a framework for determining the maturity of the deployment of cognitive computing systems in the public sector. The authors are motivated by the idea that cognitive computing systems in the public sector are stymied by many problems faced by both private firms and those that operate only in the public sector, including stakeholder groups who have conflicting goals and demand full transparency. The authors' approach to cognitive computing systems based on maturity models centered on the public sector seeks to acknowledge and address these problems, while providing a way to evaluate, assess, and give direction to such initiatives.

\section{Outlook}

This minitrack focuses on how digital transformation happens in government, fundamentally changing how government information and services operate and deliver value to citizens and organizations. We would like to thank all the authors for the large number of submissions this year. Sifting through the papers that have been accepted in a multi-stage review process promises to be a very good basis for an interesting, scientifically sound, and practice-oriented discussion. 